\title{
DESCARTES: LA IMAGINACIÓN Y EL MUNDO FÍSICO
}

CLAUDIA LORENA GARCIA

INSTITUTO DE INVESTIGACIONES FLLOSÓFICAS

UNIVERSIDAD NACIONAL AUTÓNOMA DE MÍxICO

Descartes considera que hay ciertos aspectos del mundo físico que podemos tanto imaginar como percibir sensorialmente de manera clara y distinta; a saber, algunos de los modos de la extensión - por ejemplo-, ciertas formas, figuras o movimientos. ${ }^{1}$ Sin embargo, veremos que Descartes también opina que existen otras entidades físicas que ni la imaginación ni la percepción sensible pueden presentar de manera clara y distinta; entidades que sólo pueden ser percibidas de manera clara y distinta por el intelecto puro, tales como las sustancias extensas o la divisibilidad indefinida de éstas y de sus modos. Empero, sostener ambas tesis entraña un problema serio para Descartes puesto que él también sostiene que la idea clara y distinta de cualquier entidad - por ejemplo, de una forma- tiene que contener las propiedades esenciales de esa entidad —en nuestro ejemplo, la idea de esa forma, para poder ser clara y distinta, tiene que contener la propiedad que (en tanto que magnitud) esa forma tiene de ser indefinidamente divisible. ${ }^{2}$ Parecería entonces que - en contra de un gran número de afirmaciones explícitas de Descartes- ${ }^{3}$ no puede haber una idea clara y distinta de esa forma en la imaginación, puesto que existe al menos una propiedad esencial de ese modo que no puede ser imaginada clara y distintamente.

Aquí examinaré este problema y mostraré que Descartes tiene todos los elementos para darle una solución. Sostendré que Descartes distingue dos sentidos de la palabra "contener" —aplicables a una misma idea-y que,

1 Usaré aquí la siguiente abreviación de las ediciones de las obras de Descartes: AT Oeuvres de Descartes. Editadas por Ch. Adam y P. Tannery. 12 vols. Paris: Cerf, 1897-1913; reimpresión, París: Vrin, 1957-1958. Emplearé el estilo comúnmente aceptado para citar porciones del texto de las ediciones de las obras de Descartes. [Las traducciones al castellano son mías.]

2 Véanse por ejemplo: AT III 213-214 y AT III 356, AT VIII-1 15, AT VIIl-1 78-79.

3 La cuestión acerca de si las ideas de la extensión y/o de sus modos son innatas, o si son o pueden ser adventicias, no será abordada aquí. 
en uno de estos sentidos, puede decirse que la idea clara y distinta de una cosa no necesita contener todas las propiedades esenciales de esa cosa.

En este ensayo examinaré primero los conceptos cartesianos centrales y sus interrelaciones - conceptos tales como el de modo, imaginación, percepción sensible, y entendimiento-, para posteriormente proceder al planteamiento del problema. Después presentaré en detalle la solución, lo cual me llevará a examinar, en Descartes, las nociones de idea, de claridad y distinción, y de noción simple, proponiendo una interpretación verosímil de estas nociones. Finalmente, examinaré en detalle la solución propuesta al problema central de este artículo, y algunos de los problemas que ésta pueda tener.

\section{Los modos de las sustancias}

Dentro de la clase general de cosas que "deben de inherir en algo para poder existir" (AT VI 22), Descartes distingue los modos de los atributos. ${ }^{4}$ Los atributos de una sustancia son aquellas propiedades generales que siempre permanecen invariables ${ }^{5}$ (por ejemplo, duración, existencia, extensión y pensamiento en general); mientras que un modo es una modificación de una sustancia que es capaz de variación y cambio ${ }^{6}$ (por ejemplo, la forma y el tamaño de un cuerpo, o los diferentes pensamientos de una mente finita particular).

Asimismo, nuestro conocimiento de los modos depende del de las sustancias de una manera especial: una sustancia puede ser concebida clara y distintamente aparte de su modo, pero el modo no puede ser concebido clara y distintamente aparte de la sustancia de la cual es modo: "la naturaleza de un modo (natura modi) es tal que no puede ser entendido de ninguna manera a menos que el concepto de la cosa (conceptum rei) de la cual es un modo está incluido en su propio concepto" (AT VIII-2 355). ${ }^{7}$ En cambio, nuestro conocimiento de una sustancia sí depende del de sus atributos: no sólo es que no podemos concebir clara y distintamente un atributo a menos que la noción de sustancia en general esté contenida en su concepto, sino

4 Aquí me centraré exclusivamente en la caracterización estricta de los atributos en Descartes, de acuerdo con la cual los atributos son claramente distinguibles de los modos. Sin embargo, a veces Descartes usa "atributo" en un sentido no estricto para referirse tanto a los atributos (en sentido estricto) como a los modos. Véanse, por ejemplo, AT VII 222 y AT VIII-2 348.

5 Véase AT VIII-1 26. Dios, por ejemplo, no tiene modos, sino sólo atributos, puesto que no hay variaciones en Dios. (Ibid.)

6 Véase AT VIII-2 348.

7 Véase también AT VIII-1 29. 
que además no podemos "formar una idea clara y distinta de la sustancia si excluimos de ella el atributo en cuestión". (AT VIII-1 30) ${ }^{8}$

Ahora bien, puesto que, como veremos más adelante, una idea es clara y distinta sólo si muestra a su objeto exclusivamente en términos de -por lo menos algunas de- sus propiedades esenciales, y dado que la idea clara y distinta de un modo debe contener el concepto de la cosa o sustancia de la cual es modo, se sigue que es esencial a un modo que inhiera en la sustancia en la cual de hecho inhiere.

\section{La imaginación}

Descartes no usa el término "imaginación" en el mismo sentido en todos sus escritos. A veces lo usa para referirse a una facultad de la mente por la que se pueden tener ideas que son como sensaciones; en este sentido, que una idea pertenezca, por así decirlo, a la imaginación, depende exclusivamente de la manera en la que presenta su objeto. En este sentido, imaginar algo es simplemente presentarlo de cierta manera, por ejemplo, por medio de una imagen; ${ }^{9}$ y la distinción entre la imaginación y la percepción sensible se desvanece, puesto que con frecuencia Descartes describe esta última de la misma forma: sentir es concebir de una manera pictórica y, en general, como lo hacen las sensaciones. Éste es el sentido técnico de "sentire" que Descartes introduce en la segunda Meditación: aun si no tuviera un cuerpo, y fuese falso que veo rojo, sería verdadero que me parece que veo rojo. ${ }^{10}$ Llamaremos a éste "el sentido amplio de imaginación" que abarca también la percepción sensible.

Pero en muchos otros pasajes, Descartes usa el término "imaginación" de manera tal que la imaginación y la percepción sensible son diferentes facultades de la mente puesto que tienen diferentes historias causales. Así, en la Conversación con Burman, Descartes explica:

en la percepción sensorial las imágenes son impresas por los objetos externos que están realmente presentes, mientras que en la imaginación las imágenes son impresas por la mente sin ningún objeto externo. (AT V 162) ${ }^{11}$

8 Cuando intentamos concebir una sustancia finita sin incluir su atributo principal (la extensión, en el caso de la sustancia corpórea), la idea resultante es confusa; véase AT VIII-1 31 y AT IX-2 53.

9 Por ejemplo, en una carta a Mersenne, Descartes explica: "Cualquier cosa que concebimos sin una imagen es una idea de la mente pura, y cualquier cosa que concebimos con una imagen es una idea de la imaginación." (AT III 395; el subrayado es mío.) Véase también AT VII 28.

10 Véanse AT VII 29 y AT VIII-2 360.

11 Véanse también AT III 361, AT IV 311, y AT V 162-163. 
Llamaremos a este "el sentido estrecho de imaginación". En este sentido, la imaginación y la percepción sensible son diferentes, aunque tienen en común la manera en que presentan sus objetos. Por claridad, usaré los términos "imaginación $n_{e}$ " e "imaginación $n_{a}$ " para indicar cuándo usaremos aquí "imaginación" en el sentido estrecho o en el amplio respectivamente.

\section{La imaginación i $_{\text {y }}$ las formas}

Descartes de hecho afirma en una variedad de pasajes que la imaginación $n_{a}$ puede percibir clara y distintamente algunos modos de la extensión. Por ejemplo, con respecto a la imaginación ${ }_{e}$, Descartes sostiene, en la quinta Meditación:

La cantidad continua [...] es algo que imagino distintamente. Es decir, imagino la extensión de la cantidad (o, más bien, de la cosa que está cuantificada) en largo, ancho y profundidad. (AT VII 63) ${ }^{12}$

Asimismo, Descartes también sostiene que podemos percibir sensorialmente algunos modos de la extensión de manera clara y distinta. Las ideas sensoriales, de acuerdo con Descartes, nos presentan no sólo colores, olores, texturas, etc., sino también formas, tamaños, figuras, etc. En los Principios, por ejemplo, cuando Descartes está explicando por qué cometemos el error de pensar que los cuerpos tienen colores, él dice:

Hay muchos otros aspectos, tales como el tamaño, la forma y el número, de los cuales percibimos claramente que están realmente, o por lo menos, posiblemente presentes en los objetos de manera tal que corresponden exactamente a nuestra percepción sensorial. (AT VIII-1 34; el subrayado es mío) ${ }^{13}$

El error consiste en juzgar que los colores son como las formas o las figuras las cuales sí pueden existir en los objetos. Lo importante de este pasaje es que implica que podemos con claridad percibir sensorialmente los modos de la extensión - lo cual no implica que los cuerpos siempre tienen la misma forma o el mismo tamaño que percibimos sensorialmente, sino que solamente implica que puede haber cuerpos que los tengan. ${ }^{14}$

12 Véanse también AT III 692, AT VII 28, AT VII 73, y AT VIII-134.

13 Véase también AT III 666.

14 Recuérdese que, de acuerdo con Descartes, "todo lo que percibimos claramente es verdadero, y por tanto [podemos concluir que] existe si percibimos que no puede no existir [como en el caso de Dios]; o que puede existir si percibimos que su existencia es posible" (AT III 544 545). Véase también AT III 215. 


\section{La imaginación $n_{a}$ y el entendimiento}

Hasta ahora hemos mostrado que, de acuerdo con Descartes, la imaginación $n_{a}$ nos permite percibir de manera clara y distinta algunos modos de la extensión. Pero el entendimiento puro también contiene una idea clara y distinta de la extensión y de sus modos. Asimismo vimos que la imaginación $n_{e}$ y la percepción sensible se asemejan en la manera en la que presentan sus objetos: por medio de una imagen o, en general, como una sensación. El entendimiento o intelecto, en cambio, no necesita de imágenes ni de ninguna modalidad sensible para percibir sus objetos. ${ }^{15}$

El entendimiento y la imaginación $\mathrm{n}_{a}$ difieren en otros importantes aspectos. Primero, existen fuertes razones para creer que, en Descartes, la imaginación $\mathrm{n}_{a}$, en sentido estricto, no hace uso de algunos de los recursos conceptuales que son característicos del entendimiento. Por ejemplo, Descartes sostiene que cualquier inferencia racional - hecha sobre la base de la información puramente imagística ${ }_{a}$ propoŕcionada por la percepción sensorial- pertenece al intelecto, en sentido estricto. Así, en el Conjunto sexto de respuestas, Descartes distingue "tres grados de respuesta sensorial", de los cuales explica:

El primero se limita a la estimulación inmediata de los órganos sensoriales por los objetos externos [...] El segundo grado comprende todos los efectos inmediatos producidos en la mente como resultado de estar unida a un órgano corporal [...] Tales efectos incluyen las percepciones de dolor, placer, sed, hambre, colores, sonidos [...] El tercer grado incluye todos los juicios acerca de las cosas externas. (AT VII 436-437)

El segundo grado comprende no sólo la percepción de las llamadas "cualidades sensibles o secundarias", sino también la percepción de una extensión finita. Esto es claro por su descripción del segundo y tercer grados: el color que se nos presenta en el segundo, explica Descartes, tiene una cierta extensión, límites, etc.; y el razonamiento que nos permite calcular el tamaño y forma reales del objeto externo - un razonamiento que pertenece al tercer grado y que "depende solamente del intelecto" (AT VI 437-438) — se basa en la extensión, los límites, etc., del color experimentado. ${ }^{16}$

Ahora bien, dado que, en la imaginación $\mathrm{n}_{a}$, en sentido estricto, no hacemos uso de esta capacidad intelectual, se sigue que, de acuerdo con Descartes, no podemos imaginar sustancias, ya que nuestro conocimiento de la sustancia

15 Véase AT III 392-393.

16 Véanse AT VII 32, AT VII 437 y AT VIII-2 360-361. 
misma no es inmediato, sino que depende de una inferencia racional a partir de la percepción de sus atributos o de sus modos. ${ }^{17}$

En segundo lugar, la imaginación $n_{a}$ tiene otras limitaciones conceptuales que no tiene el entendimiento; por ejemplo, aunque sí puedo imaginar $r_{e}$ un triángulo, "si quiero pensar acerca de un quiliágono, aunque entiendo que es una figura de mil lados [...] no puedo de la misma manera imaginar los mil lados" (AT VI 72). En cambio, sí puedo tener una idea clara y distinta del quiliágono en el entendimiento -es decir, entender y demostrar claramente sus propiedades esenciales. ${ }^{18}$

En tercer lugar, mientras que la imaginación $\mathrm{n}_{\alpha}$ no puede, el entendimiento sí puede percibir la esencia de las sustancias corporales. La idea clara y distinta de un cuerpo - - es decir, la idea de su esencia - que pertenece al entendimiento presenta, en último análisis, una construcción matemática; es decir, una sustancia que tiene ciertas propiedades matemáticas, y ciertas capacidades matemáticamente descriptibles, tales como la capacidad de adquirir un número indefinidamente grande de formas. Empero, la imaginación jamás podrá alcanzar esta percepción clara y distinta de la esencia de una sustancia corporal. ${ }^{19}$

\section{El problema}

Es esencial para la extensión finita ser indefinidamente divisible. En la sexta Meditación, por ejemplo, Descartes dice que "un cuerpo es por su misma naturaleza siempre divisible" (AT VII 85-86). ${ }^{20}$ La forma y el tamaño de un cuerpo son también indefinidamente divisibles. ${ }^{21}$ La divisibilidad de la

17 En los Principios, Descartes afirma que, una vez que percibimos un modo o un atributo, "podemos inferir (concludimus) que debe haber una cosa existente o sustancia a la cual se le pueda atribuir [el modo o atributo]" (AT VIII-1 25). Véanse también AT VII 161, AT VII 222 y AT VIII-1 8.

18 La idea del entendimiento es clara puesto que "muchas de sus propiedades pueden ser demostradas muy clara y muy distintamente" (AT VII 384-385).

19 Esto es precisamente lo que Descartes concluye en la segunda Meditación, al examinar su idea de un pedazo de cera: en tanto que es un cuerpo, la cera es "simplemente algo extenso, flexible y mudable" (AT VII 31); es decir, algo que es capaz tanto de innumerables cambios de forma, como "de ser extenso de muchas más maneras de las que podré abarcar en mi imaginación". (Ibid.)

20 Véase también AT VII 13.

21 Véase AT VIIl-1 23: el tamaño, por ejemplo, es "extensión en largo, ancho y profundidad," es decir, una cantidad particular de la extensión tridimensional. También véase AT III 356, en donde Descartes dice que tanto la forma como el movimiento "pueden ser divididos en muchos componentes", y AT III 475: "Es imposible concebir una forma y al mismo tiempo negar que tiene una extensión." 
extensión finita y de sus modos -en contraste con su división real- ${ }^{22}$ se sigue de su concepción estrictamente matemática como magnitudes. ${ }^{23}$

Sin embargo, la divisibilidad indefinida de la extensión no puede ser ni imaginada $_{e}$, ni percibida por los sentidos, por la misma razón por la que estas facultades no pueden percibir un quiliágono o la capacidad de un cuerpo de adquirir un número indefinidamente grande de formas. Además, en la sección 1 vimos que la idea clara y distinta de un modo debe contener el concepto de la sustancia de la cual es un modo; y en la sección 4 vimos que la percepción de una sustancia no pertenece a la imaginación $n_{a}$, sino al entendimiento.

El problema entonces es que parece que es imposible que la imaginación $n_{a}$ pueda contener ideas claras y distintas de los modos de la extensión, ya que no puede percibir algunos de sus aspectos esenciales.

En lo que sigue, sostendré que Descartes puede encontrar una solución a este problema, puesto que acepta: (a) que existe un sentido de la palabra "contener" en la teoría cartesiana de las ideas, de acuerdo con el cual puede decirse que es posible que tengamos una idea clara y distinta de $X$ que no contenga todas las características esenciales de $X ; y$ (b) que las nociones de la extensión y las de sus modos son primitivas; 0 , como Descartes lo expresa, que éstas son "naturalezas simples". Examinemos cada una de estas tesis por separado.

\section{Las ideas y su claridad}

Descartes afirma que es posible tener una idea clara y distinta de Dios que no contenga todos sus atributos esenciales. ${ }^{24}$ Para explicar cómo es que Descartes realmente puede hacer esta afirmación, examinaremos primero su noción de idea.

\section{(A) Ideas}

Descartes introduce la noción de idea en la tercera Meditación, en donde afirma que las ideas son aquellos "de mis pensamientos [que] son como

22 La división real de un cuerpo (al igual que los cambios de forma) ocurren cuando choca contra otros cuerpos. Véase AT III 649, AT VIII-1323, AT VIII-1 52 y AT XI 38.

23 Véanse AT VIII-1 15, AT XI 36 y AT VIII-1 45. Además, en una carta a Mersenne del 28 de octubre de 1640, Descartes dice que el término "cuerpo" significa "una cosa que tiene largo, ancho y profundidad, y que por tanto no puede componerse de cosas indivisibles, puesto que una cosa indivisible no puede tener largo, ancho, o profundidad" (AT III 213-214; el subrayado es mío); es decir, no puede tener tamaño (AT VIII-1 23) o forma.

24 Véanse por ejemplo: AT V 136-137, AT VII 152, AT VII 220-222, AT VII-1 12 y AT VIII-1 26. 
imágenes de cosas (tanquam rerum imagines)" (AT VII 37). Más adelante, en la misma Meditación, Descartes descarta el "imagines", y dice que "no puede haber ideas que no sean como si de cosas (tanquam rerum)" (AT VII 44). La versión francesa de este pasaje dice lo siguiente: "no puede haber ninguna [idea] que no parezca representarnos una cosa" (AT IX-1 34-35). Por tanto, las ideas son pensamientos que son tanquam rerum, como si de cosas; es decir, pensamientos que aparentan representar algo.

Además, una idea puede ser considerada desde diferentes puntos de vista, de acuerdo con Descartes. Por ejemplo, Descartes le dice a Arnauld que las ideas pueden ser consideradas o material o formalmente:

cuando las consideramos en tanto que representan algo las estamos considerando [...] formalmente. Sin embargo, si las estuviesemos considerando [...] simplemente como operaciones del intelecto, entonces podría decirse que las estamos considerando materialmente. (AT VII 232)

Normalmente, una idea considerada materialmente se interpreta como la idea en tanto que es un modo de pensar del cual no se considera su contenido. ${ }^{25}$ Sin embargo, el único pasaje que tal vez podría sostenerla se encuentra en la tercera Meditación, en la que Descartes caracteriza la idea considerada materialmente de la siguiente manera: "En tanto que [...] las ideas son simplemente modos de pensar [i.e., consideradas materialmente] no reconozco ninguna desigualdad entre ellas" (AT VI 40). Empero, en los Principios, Descartes modifica este enunciado, y dice que nuestras ideas, "en tanto que son solamente modos de pensar [i.e., consideradas materialmente], no difieren mucho unas de las otras (non multum a se mutuo diferre)" (AT VII-1 11). Si, en efecto, considerar las ideas materialmente fuese considerarlas sin tomar en cuenta sus contenidos, entonces, consideradas así, las ideas no diferirían de ninguna manera unas de otras.

Además, veremos más adelante que es necesario descartar esta manera de interpretar la noción cartesiana de idea-considerada-materialmente para poder construir una manera coherente de entender lo que Descartes responde a las objeciones que Arnauld formula en contra de la tesis de que existen ciertas ideas que son materialmente falsas. ${ }^{26}$ Veremos también que la distinción entre una idea considerada materialmente y la idea conside-

25 Si lo entiendo correctamente, Norman Wells comparte esta confusión, en su "Objective Reality of Ideas in Descartes, Caterus, and Suarez," Journal of the History of Philosophy, no. 28, 1990, pp. 33-61; esp. 45-46. Thomas Lennon también la tiene: "The Inherence Pattern and Descartes' Ideas", Journal of the History of Philosophy, no. 12, 1974, pp. 43-52; esp. 47; y E.J. Ashworth, "Descartes' Theory of Objective Reality", New Scholasticism, no. 49, 1975, pp. 331340; esp. 335.

26 Véase AT VII 232-234. 
rada formalmente es una distinción entre (respectivamente): (a) la idea en tanto que presenta un cierto contenido a nuestra conciencia, y en tanto que parece representarnos una cosa (res); y (b) la idea en tanto que representa (y no como el objeto representado); es decir, la idea en su función representativa.

Ahora bien, Descartes hace otra distinción en la manera de considerar una idea:

"Idea" puede ser considerada materialmente, como una operación del intelecto, en cuyo caso no puede decirse que sea más perfecta que yo. Alternativamente, puede ser considerada objetivamente, como la cosa que tal operación representa. (AT VII 8)

En resumen, hay tres diferentes maneras de considerar una idea: (a) materialmente, como un modo de pensar; i.e., como un episodio consciente particular; (b) formalmente, en tanto que representa, o en su función representativa, y (c) objetivamente, como la cosa representada. ${ }^{27}$

En otros pasajes, Descartes hace otra distinción que, de cierta manera, corresponde a esta distinción tripartita. Ésta es la distinción entre el contenido implicito de una idea y su contenido expllcito. Por ejemplo, en el Quinto conjunto de respuestas, Descartes dice:

Una vez que la idea del Dios verdadero ha sido concebida, aun cuando detectemos más perfecciones en él que no habíamos notado todavía, esto no significa que hemos aumentado la idea de Dios; simplemente la hemos hecho más distinta y explícita, ya que, suponiendo que la idea original era verdadera, debe haber contenido ya todas estas perfecciones. (AT VII 373; el subrayado es mío)

Es posible, por tanto, que una idea contenga implícitamente muchas perfecciones que ignoramos. ${ }^{28}$ De hecho, la tesis de que es posible que las ideas -incluso las claras y distintas- contengan implícitamente ciertos elementos que ignoramos, es recurrente en Descartes. ${ }^{29}$

27 Nótese que la distinción entre una idea considerada materialmente, la idea considerada formalmente, y la idea considerada objetivamente, no es una distinción entre tres diferentes tipos de ideas. Más bien, es una distinción entre tres diferentes maneras de considerar la misma idea. Véase Monte L. Cook, "The Alleged Ambiguity of 'Idea' in Descartes' Philosophy", The Southwestern Journal of Philosophy, no. 6, 1975, pp. 87-94.

28 Algo similar le dice Descartes a Mersenne en una carta con fecha del 23 de junio de 1641: "si de una idea construida infiriese lo que explícitamente introduje en ella, estaría dando por sentado lo que trato de probar; pero no es lo mismo si extraigo de una idea innata algo que estaba contenido implícitamente en ella pero que no había notado al principio" (AT III 383; el subrayado es mío).

29 Véase AT VII 147, en donde Descartes afirma que las ideas oscuras y confusas contienen (implícitamente) elementos que ignoramos. Las ideas claras y distintas también pueden 
Existe una tercera distinción en Descartes que está relacionada con aquella distinción tripartita (i.e., entre idea considerada material, formal y objetivamente). Descartes hace esta tercera distinción en respuesta a la objeción de Arnauld, quien dice que no puede haber ideas materialmente falsas -es decir, ideas que representan una no-cosa como una cosa-,, 30 ya que una idea siempre debe conformarse al objeto que representa. En otras palabras, para que una cosa pueda ser el objeto representado por una idea, el objeto debe poseer todas las propiedades contenidas en la idea -aunque no necesariamente sólo ésas. En respuesta a esta objeción, Descartes hace la distinción entre aquello a lo que una idea se refiere y aquello a lo que la idea se conforma. Descartes dice:

Creo que necesitamos hacer una distinción; puesto que con frecuencia sucede, en el caso de ideas oscuras y confusas [algunas de las cuales son falsas] [...] que una idea refiere a algo diferente de aquello de lo cual la idea realmente (revera) es. (AT VII 233)

Por el contrario, de la idea clara y distinta de Dios "no se puede decir que refiera a algo con lo cual no se conforme (conformis)" (ibid.). Considerando estos dos pasajes en conjunción, podemos inferir que aquello a lo cual una idea se conforma es aquello de lo cual la idea realmente es; esto es, el objeto realmente representado.

Nótese que la distinción referirse/conformarse corresponde a la distinción idea-considerada-materialmente/formalmente, lo cual implica que hay un sentido en el que la idea, considerada materialmente, es acerca de algo -es decir, tiene contenido-, puesto que, considerada así, la idea refiere a algo. ${ }^{31}$

Con respecto a una idea considerada objetivamente -es decir, la idea como el objeto representado- existe otra conexión conceptual que no hemos considerado todavia; a saber, que lo que una idea representa, de manera

contener implícitamente perfecciones que ignoramos. Véanse AT VII 220-226 y AT VII 373. Véase también lo que Descartes le dice a Caterus acerca de la insuficiencia de cualquier idea de Dios que podamos tener: AT VII 133.

30 Véase AT VII 43.

31 Debe entenderse con cuidado la frase "una idea se refiere a $x$ ". Ésta no puede entenderse. en el sentido comúnmente usado en semántica, de acuerdo con el cual, aplicado a, por ejemplo, un nombre, se dice que el nombre refiere a cierta entidad. En el presente contexto -a saber, la discusión con Arnauld acerca de la falsedad material de las ideas (AT VII 232-235) - está claro que cuando Descartes dice que una idea se refiere a algo él simplemente quiere decir que la idea parece representar algo que puede ser diferente de aquello que es verdaderamente representado por la idea. 
primaria, es una esencia. Por ejemplo, a Gassendi Descartes le dice: "Una idea representa la esencia de una cosa (rei essentiam)" (AT VI 371). ${ }^{32}$

Ahora bien, existe en Descartes una conexión entre cierta facultad de nuestras mentes, y las ideas consideradas formalmente. Para entender la naturaleza de esta conexión, debemos notar, en primer lugar, que Descartes sostiene que la capacidad que tenemos de formar ideas claras y distintas constituye una facultad real de nuestras mentes. Por ejemplo, a Hyperaspistes Descartes le dice:

La mente percibe dos cosas, una aparte de la otra, como cosas completas, por medio de una facultad real que posee; y [...] la mente aprehende dos cosas de una manera confusa, como una sola cosa, por medio de la carencia de esa misma facultad. (AT III 434)

Dado que la percepción de una cosa como una cosa completa se obtiene en la percepción o idea clara y distinta de esa cosa, ${ }^{33}$ y puesto que la mente percibe una cosa completa sólo a través del uso de cierta facultad, se sigue que es necesario que poseamos esta facultad para poder tener ideas claras y distintas. Cuando usamos esta facultad para presentar explícitamente un objeto a nuestra conciencia, la idea es clara y distinta. Sin embargo, dado que somos finitos y falibles, en ocasiones no usamos esta facultad, y cuando esto sucede la idea resultante es oscura y confusa, o peor aun, materialmente falsa. ${ }^{34}$

Una idea clara y distinta, por ende, surge del uso de cierta facultad de percepción. ${ }^{35}$ Pero -como veremos más adelante cuando examinemos la noción de claridad y distinción - para que una idea pueda ser clara y distinta, la idea debe presentar su objeto exclusivamente en términos de sus propiedades esenciales. Por tanto, dado que (a) una idea clara y distinta es aquella que presenta sus objetos de esta manera y que resulta de la aplicación de esta facultad, y (b) una idea confusa es la que presenta sus

32 Véanse también AT IV 350, AT VII 8, AT VII 64-65 y en donde Descartes afirma o sugiere que el objeto representado es una esencia.

33 Véase la discusión con Arnauld acerca de las cosas completas y su conexión con las ideas claras y distintas en AT VII 220-227.

34 Véanse AT III 435 y AT VII 44, en donde Descartes dice que las ideas materialmente falsas (que son oscuras) "están en mí únicamente debido a una deficiencia y carencia de perfección en mi naturaleza". Véanse también AT VI 38 y AT VII 46.

35 Véase también AT VIII-1 16. A esta facultad Descartes la llama la "facultad de percepción", y la distingue de la facultad de asenso, o voluntad. Véase AT VIII-1 21. Nótese que, de acuerdo con Descartes, los juicios son actos de la voluntad, pero las ideas no lo son. (Véanse AT VII 376-377 y AT VIII-1 17.) Las ideas nos presentan un contenido explícito para nuestra consideración. Entonces podemos juzgar -decidir a asentir- que esta idea se asemeja (o no se asemeja) a algo en el mundo. 
objetos en términos de sus propiedades accidentales, ${ }^{36}$ y que se origina cuando no se usa tal facultad, se sigue que la facultad de percepción que nos permite percibir un objeto clara y distintamente es la facultad que nos permite descubrir las propiedades esenciales de ese objeto.

Podemos ahora percibir la conexión que existe entre esta facultad y las ideas consideradas formalmente. Hemos visto que considerar una idea de esta manera es considerarla en tanto que representa algo; ${ }^{37}$ y que esto es distinto de considerar la idea objetivamente, es decir, como la cosa representada. ${ }^{38}$ Por tanto, considerar la idea formalmente es considerarla exclusivamente en su función representativa -es decir, considerar aquél de sus aspectos en virtud del cual la idea representa. También hemos visto que, de acuerdo con Descartes, nuestras ideas - al menos nuestras ideas claras y distintas - representan un conjunto de propiedades cada una de las cuales pertenece a la esencia de un objeto, y no todas las cuales están necesariamente presentes de manera explícita en la conciencia del cognoscente. Pero el único candidato en la ontología cartesiana que puede realizar esta función de representar —entendida de esta manera- es la facultad que nos permite formar ideas claras y distintas que representan esencias verdaderas.

De todos los pasajes anteriores, entonces, surge un panorama general, de acuerdo con el cual las ideas pueden ser consideradas de tres maneras diferentes:

(a) Materialmente, como un suceso mental que presenta algo a nuestra conciencia. Considerada así, el contenido de la idea es explícito, y la idea parece representar, o refiere, a algo. Las restricciones que gobiernan las ideas, cuando se las considera materialmente, no necesariamente son de naturaleza lógica, puesto que una idea considerada materialmente es, de acuerdo con Descartes, la idea considerada como un producto de nuestras mentes finitas y falibles. ${ }^{39}$ Así considerada, no existe siempre la necesidad de postular una causa para la idea, excepto la habilidad de nuestras mentes de concebir y combinar contenidos de maneras que no están necesariamente de acuerdo con los principios de representación correcta —es decir, los que gobiernan la representación

36 Véase la discusión en la segunda Meditación, en la que Descartes considera la idea de un pedazo de cera en la que la cera se presenta en términos de sus características sensibles, tales como la forma o el tamaño particular que tiene en ese momento, y que no son esenciales a la cera (entendida como un cuerpo). A esta idea Descartes la llama "oscura y confusa" (AT VII 30-32).

37 Véanse AT VII 40, AT VII 232 y AT VIII-1 11.

38 Véase AT VII 8.

39 Véanse AT VII 8 y AT VII 40. 
de una cosa por medio de sus propiedades esenciales. ${ }^{40}$ Asimismo, una idea considerada materialmente es tanquam rerum puesto que parece representar algo; lo cual quiere decir que las cosas que percibimos son siempre percibidas como posibles. Esto significa que no puede haber ideas de cosas imposibles cuya imposibilidad sea obvia o aparente a la conciencia. Ésta es una de las restricciones que gobiernan una idea considerada materialmente. ${ }^{41}$

(b) Objetivamente, como el objeto realmente representado y al cual la idea se conforma. Así considerada, la idea tiene un contenido implícito parte del cual puede no estar presente explícitamente en nuestra conciencia. ${ }^{42}$ Puede decirse que la idea considerada objetivamente es la idea considerada como una entidad lógicamente ideal; es decir, como una entidad constituida de tal manera que consistentemente obedece ciertos principios lógico-normativos característicos de nuestra facultad de percepción correcta; es decir, los que gobiernan la percepción de una cosa en términos de sus propiedades esenciales.

(c) Formalmente, como la función representativa de la idea. Este aspecto de una idea consiste en nuestra posesión de una facultad de percepción; es decir, de una facultad de formación correcta de ideas.

Vemos entonces que una idea, de acuerdo con Descartes, no es sólo un episodio mental particular que presenta cierto contenido a nuestra conciencia (idea considerada materialmente). Considerada desde otras perspectivas, la idea es también una facultad especifica (idea considerada formalmente), y un contenido implícito (idea considerada objetivamente), i.e.,

40 Por ejemplo, es posible que las propiedades contenidas explícitamente en una idea sean todas accidentales —en cuyo caso la idea será oscura y confusa- o que no puedan ser todas poseldas por una misma cosa (que sean incompatibles) —en cuyo caso la idea es materialmente falsa.

41 Hay ideas de cosas imposibles cuya imposibilidad no es inmediatamente aparente, en cuyo caso las ideas son materialmente falsas. Pero aun en este caso, estas cosas son concebidas como posibles.

42 En mi artículo "Descartes on Mental Representation", he argüído extensamente que esta distinción de los contenidos de una idea (es decir, idea considerada materialmente e idea considerada objetivamente) es necesaria para articular las nociones de falsedad material, y de oscuridad y confusión en Descartes; y que él era plenamente consciente de esta necesidad. Un número considerable de autores han aceptado que existe en Descartes esta distinción de contenidos. Por ejemplo, Calvin Normore, en su articulo "Meaning and Objective Being: Descartes and His Sources", en Essays on Descartes' Meditations, Amelie Oksenberg Rorty (ed.), University of California Press, Berkeley, Los Ángeles, Londres, 1986, p. 227, distingue la estructura superficial de una idea de su estructura profunda. También Alan Gewirth, en su "Clearness and Distinctness in Descartes", Philosophy, no. 18, 1943, pp. 17-36, distingue el contenido directo del contenido interpretativo de una idea. 
aquel contenido que podría ser generado a través de la aplicación correcta de esa facultad al contenido explícito. Gewirth dice que una idea considerada objetivamente (o lo que él llama el "contenido directo" de una idea) es la idea considerada normativamente. ${ }^{43}$

\section{(B) Ideas claras y distintas}

En las Cuartas respuestas, Descartes le dice a Arnauld que, de una idea clara y distinta, "no puede decirse que refiera a algo a lo cual no se conforme" (AT VII 233); es decir, que en una idea clara y distinta el contenido explícito (lo que la idea parece representar) debe ser idéntico con al menos parte de su contenido implícito (lo que la idea realmente representa). Sin embargo, no puede ser el caso - como algunos autores sostienen- ${ }^{44}$ de que, para que una idea sea clara y distinta, el contenido explícito de una idea siempre debe ser completamente idéntico al contenido implícito, puesto que, como vimos, Descartes acepta que podemos tener una idea clara y distinta de Dios, ${ }^{45}$ aun cuando podemos concebir tan sólo algunos de sus atributos. ${ }^{46}$

Existen dos características adicionales de las ideas claras y distintas: (a) que no puede haber auto-contradicción en ellas; ${ }^{47}$ y (b) que "una existencia posible está contenida en el concepto o idea de cualquier cosa que entendemos clara y distintamente" (AT VII 116). ${ }^{48}$

Otro aspecto notorio de las ideas claras y distintas es que podemos estar seguros de que éstas contienen esencias verdaderas e inmutables. Esto es precisamente lo que Descartes le dice a Burman: "Todo aquello que, en una quimera, concebimos clara y distintamente, es una entidad verdadera. No es ficticia, puesto que tiene una esencia verdadera e inmutable." (AT V 160)

Además, vimos ya que las ideas claras y distintas son el producto del uso de cierta facultad de percepción ${ }^{49}$ que nos permite concebir las cosas en términos de sus propiedades esenciales, mientras que la oscuridad y la confusión en nuestras ideas surge cuando no usamos correctamente esta

43 Véase Alan Gewirth, "Clearness and Distinctness", pp. 25-26.

44 Por ejemplo, Alan Gewirth, en su articulo "Clearness and Distinctness", p. 24, dice: "the clearness and distinctness of an idea may be said to consist in the 'equality' of its direct and interpretive contents".

45 Véase por ejemplo AT VII 114.

46 Véase AT VII 152. Además, vimos que Descartes le había dicho a Gassendi que la idea clara y distinta del Dios verdadero podría contener implícitamente muchas perfecciones que ignoramos (AT VII 371). Véase también AT VII 224: "Podemos entender clara y distintamente que un triángulo en un semicírculo sea un triángulo rectángulo, sin darnos cuenta de que el cuadrado de la hipotenusa es igual a [la suma de] los cuadrados de los otros dos lados."

47 Véase AT VII 152.

48 Véanse también AT III 544-545 y AT VII 119.

49 Véase AT III 434. 
facultad; por ejemplo, cuando concebimos un objeto en términos de sus accidentes. ${ }^{50}$

A partir de estos pasajes, podemos concluir que una idea clara y distinta tiene las siguientes características:

(1) En una idea clara y distinta, el contenido explícito está gobernado por las restricciones o principios lógicos que constituyen nuestra facultad de percepción; en cuyo caso, el contenido explícito es idéntico con al menos parte del contenido implícito - ya que, por definición, este último obedece rigurosamente estos principios.

(2) Cuando el contenido explícito obedece las restricciones lógicas constitutivas de tal facultad, la idea considerada materialmente (o como un episodio consciente) presenta al sujeto algunas - aunque no necesariamente todas - de las propiedades esenciales de una cosa, y ninguno de sus accidentes. ${ }^{51}$

\section{Las naturalezas simples}

Examinemos ahora la afirmación de Descartes de que la extensión es una naturaleza simple. En las Reglas para la dirección del espiritu, dice que

llamamos "simple" sólo a aquellas cosas que conocemos tan clara y distintamente que la mente no puede descomponerlas en otras que sean conocidas más distintamente. La forma, la extensión, el movimiento, etc., son de este tipo. (AT X 418)

Estas naturalezas simples "son todas autoevidentes y nunca contienen ninguna falsedad" (AT X 420). Más adelante, en su obra de madurez de los Principios, Descartes habla acerca de "todas las nociones simples que son los componentes básicos de nuestros pensamientos" (AT VII-1 22), entre las cuales cita "el tamaño (es decir, la extensión en largo, ancho y profundidad), la forma, el movimiento, la posición, la divisibilidad de las partes componentes y otras nociones parecidas" (AT VIII-1 23).

Asimismo, Descartes le dice a Elizabeth que

nos equivocamos si tratamos de explicar una de estas nociones en términos de otra $[\ldots]$ cada una de ellas puede ser entendida solamente por sí misma. (AT III 666)

50 Véanse AT III 435 y AT VIII-1 16.

51 Una presentación lógica rigurosa de estas ideas puede encontrarse en mi artículo "Descartes on Mental Representation", (manuscrito). 
$Y$ añade que el "uso de nuestros sentidos ha hecho que estemos más familiarizados con las nociones de la extensión, de las formas y de los movimientos, que con otras nociones" (ibid.).

\section{La solución}

Descartes tiene todos los elementos para encontrar una solución al problema que hemos estado considerando: puede decir que es posible que algunas ideas claras y distintas de los modos de la extensión pertenezcan a las facultades de la imaginación $\mathrm{n}_{e}$ y de la percepción sensible, puesto que (1) las ideas claras y distintas de estos modos no necesitan contener explícitamente todas las propiedades esenciales de estos modos; por ejemplo, la divisibilidad indefinida; y (2) además, dado que las ideas claras y distintas de estos modos son nociones simples, entonces estos modos no necesitan entenderse en términos de otras nociones, por ejemplo, la divisibilidad indefinida. En otras palabras, para poder ser clara y distinta, la idea de uno de estos modos necesita solamente contener explícitamente la naturaleza simple en cuestión - por ejemplo, la propiedad de ser una forma particular.

Examinemos esta solución. En las secciones precedentes hemos sostenido que las siguientes tesis se encuentran en Descartes: (a) algunos modos de la extensión son imaginables ${ }_{a}$ de manera clara y distinta; (b) la idea clara y distinta de un modo debe contener el concepto de la sustancia de la cual es un modo; (c) asimismo, tal idea debe contener el concepto de divisibilidad indefinida; (d) la imaginación $n_{a}$, propiamente hablando, no tiene los recursos para generar los conceptos a los que se alude en (b) y (c).

De las tesis (b)-(d) aparentemente se sigue que ninguna idea clara y distinta de los modos de la extensión puede pertenecer a la imaginación $\mathrm{n}_{a}$. Pero ésta es, sostengo yo, una conclusión apresurada. Hemos visto que la palabra "contener" es ambigua en la teoría cartesiana de las ideas, puesto que Descartes distingue el contenido explícito del contenido implícito de una idea - es decir, la idea considerada materialmente de la idea considerada objetivamente. También vimos que Descartes sostiene las siguientes tesis con respecto a esta distinción: (e) la idea clara y distinta de $X$ debe contener explícitamente al menos algunas de las características esenciales de $X$, y ninguna de las accidentales; y ( $f$ ) esta idea clara y distinta contendrá objetiva o implícitamente todas las propiedades esenciales de $X, y$ ninguno de sus accidentes.

Así es que, para ser clara y distinta, la idea de un modo de la extensión no necesita contener explícitamente todas las características esenciales de ese modo; 52 sí debe contener objetivamente, sin embargo, todas estas carac-

52 Por ejemplo, la propiedad de ser un modo de una sustancia corporal. Véase AT VIII-2 355: "la naturaleza de un modo (natura modi) es tal que no puede ser entendido a menos que el concepto de la cosa de la cual es un modo esté incluido en su concepto". 
terísticas esenciales - algunas de las cuales sólo pueden ser percibidas por el entendimiento puro. Pero existe todavía este problema para Descartes; a saber, ¿cómo es que una idea de la imaginación puede contener implícita u objetivamente ciertas características cuyos conceptos no pertenecen a la imaginación?

Para entender cómo es que esto es posible en la teoría de Descartes, consideremos lo siguiente: cuando una idea se considera materialmente, se la considera como un episodio consciente cuyo contenido puede obedecer ciertas restricciones distintas de las restricciones logicas que son constitutivas de la percepción correcta de una cosa -0 , para ser más precisos, constitutivas de la facultad que nos permite tal percepción. En cambio, el contenido de la idea considerada objetivamente siempre y necesariamente obedece tales restricciones lógicas; considerada así, la idea es la percepción correcta de la cosa.

Por otra parte, las limitaciones perceptuales de la imaginación $\mathrm{n}_{a}$ son inherentes a la manera específica en la que presenta explícitamente sus objetos: pictóricamente o como una sensación. ${ }^{53}$ Estas limitaciones son características de cierta manera de presentar o exhibir objetos a la conciencia; pertenecen, por tanto, al dominio de la idea considerada materialmente -en particular, al conjunto de restricciones (no necesariamente lógicas) que gobiernan las maneras en las que nuestras mentes pueden o no pueden presentar algo a nuestra conciencia.

En otras palabras, lo que estoy defendiendo es que las limitaciones perceptuales de la imaginación $n_{a}$ se aplican a una de sus ideas cuando se la considera materialmente - pero no cuando se la considera objetiva o normativamente. Así considerada, el contenido de la idea depende exclusivamente de la facultad de percepción que, en principio, puede hacer uso de cualquier recurso conceptual disponible, incluyendo aquellos que, en sentido estricto, pertenecen al entendimiento.

A la inversa, Descartes afirma inequívocamente que podemos imaginar $_{a}$ clara y distintamente algunos modos de la extensión. Ahora bien, una idea considerada objetivamente es el objeto representado en términos de todas sus propiedades esenciales. Pero muchas de las propiedades esenciales de los modos de la extensión pueden ser percibidas sólo por el intelecto. Por tanto, una idea de la imaginación $n_{a}$ tendrá que contener objetivamente elementos que son puramente intelectuales.

Sugiero que esto es lo que Descartes quiere decir en los Comentarios acerca de un folleto, ${ }^{54}$ cuando afirma que "no hay nada en nuestras ideas que no sea innato a la mente [...] con la sola excepción de aquellas circunstancias

53 Véanse AT III 395, y la sección 2.

54 Notae in programma quoddam. 
que se refieren a la experiencia" (AT VIII-2 358). Sin embargo, un examen detallado de este pasaje, y de la adecuación de nuestra interpretación en relación con él, no puede llevarse a cabo aquí puesto que involucra el difícil concepto cartesiano de lo innato.

\section{Evaluación final}

Pero aún parece existir un problema. Vimos que los modos de la extensión son cantidades matemáticas en Descartes; y cualquier cantidad matemática obedece un principio como éste:

Cualquier cantidad de medida $L$ es tal que existen otras dos cantidades de medidas $M$ y $N$ tales que $O<M<L$ y $O<N<L$, y $M+N=L$.

Y es todavía un misterio si es que - y cómo es que-la noción primitiva de la

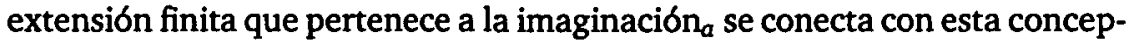
ción matemática clara y distinta de la extensión o espacio que pertenece al entendimiento puro. Hasta ahora parecería que no existe ninguna conexión inteligible entre estas dos ideas - la noción simple que se encuentra en la imaginación, y la extensión como una cantidad matemática. Por otra parte, la solución propuesta arriba presupone que la divisibilidad indefinida es una característica esencial de la extensión finita; de manera que uno tiene que mostrar que existe una conexión entre ellas.

Pero Descartes sí nos ha dicho algo acerca de esta conexión. Él dice que, aunque no podemos imaginar ${ }_{a}$ que una extensión sea indefinidamente divisible, sí podemos imaginar que sea divisible en dos, cuatro, ocho, e incluso dieciséis partes. Además, con frecuencia percibimos sensorialmente la divisibilidad de los cuerpos: "Esto es algo que es visible [...] en muchos casos" (AT II 200). ${ }^{55}$ En consecuencia, la imaginación $n_{a}$ puede presentar, no la divisibilidad indefinida de la extensión, pero por lo menos su divisibilidad hasta cierto punto. Además, la imaginación $e_{e}$ puede ayudarnos a entender que no puede haber cuerpos indivisibles, puesto que siempre podemos imaginar $_{e}$ las dos partes de cualquier extensión finita por pequeña que sea. ${ }^{56}$

Con esto, Descartes ha satisfecho el requisito de que debe existir una conexión inteligible entre la extensión finita como la naturaleza simple que se encuentra en la imaginación $\mathrm{n}_{a}$, y la divisibilidad indefinida que es propiedad de cualquier cantidad matemática. 